Article

\title{
Development of a Halogen Free Flame Retardant Masterbatch for Polypropylene Fibers
}

François Rault ${ }^{1,2, \dagger}$, Stéphane Giraud ${ }^{1,2, \dagger}$, Fabien Salaün ${ }^{1,2, \dagger, *}$ and Xavier Almeras ${ }^{3, \dagger}$

1 Université Lille Nord de France, F-59000 Lille, France; E-Mails: francois.rault@ensait.fr (F.R.); stephane.giraud@ensait.fr (S.G.)

2 Ecole Nationale Supérieure des Arts et Industries Textiles (ENSAIT)/Laboratoire Génie des Matériaux Textiles (GEMTEX), F-59100 Roubaix, France

3 Devan Chemicals, 539, Chée de Ninovesteenweg, Ronse 9600, Belgium;

E-Mail: Xavier.Almeras@devan-be.com

$\dagger$ These authors contributed equally to this work.

* Author to whom correspondence should be addressed; E-Mail: fabien.salaun@ensait.fr; Tel.: +33-320-256-464; Fax: +33-320-248-406.

Academic Editor: A. Richard Horrocks

Received: 30 November 2014 / Accepted: 28 January 2015 / Published: 9 February 2015

\begin{abstract}
The efficiency of new phosphinates, in combination with melamine cyanurate, was studied using different polypropylene textile structures. The influence of different ratios up to a total amount of $6 \mathrm{wt} \%$ in the polypropylene fiber was investigated using the limiting oxygen index (LOI) and cone calorimeter method for research purposes, while the performances were correlated to the standards FMVSS 302 (Federal Motor Vehicle Safety Standards) and DIN 4102-1 (Deutsches Institut für Normung) used more specifically for automotive and building sector.
\end{abstract}

Keywords: polypropylene fiber; flame-retardant; thermal properties; flammability

\section{Introduction}

The world consumption of polyolefins and, more specifically polypropylene (PP), represented more than 50 million tons in 2009 and is estimated to have had an average annual growth rate of $4 \%$ for the 
period from 2010 to 2020 [1]. In contrast to other polymers like polystyrene or polyvinyl chloride, PP is widely used in producing engineering plastics. Its price varies according to three elements, i.e., its alkylation value, its netback depending on the parity between high-density polyethylene and resins such as PS. Polypropylene has replaced other polymers in the production of a wide range of fibrous materials in household textiles (carpet backing and yarns, upholstery fabrics, rugs, and others), in health and medicine for care materials or disposable diapers, in protective clothing, in geo and/or agrotextiles, nonwovens, and others. Thus, the production of PP fibers represented $10 \%$ of the volume of fibers manufactured in 2007 globally. Even though the consumption of polypropylene textile materials in Europe decreased about 4.8\% from 2008 to 2009, polyolefin fibers represented 44.3\% of the consumption of man-made fiber in 2010 mainly in spunbond and meltblown (31.2\%), tapes and slit films (21.8\%), multifilaments (19.1\%) and staple fibers (20.7\%). The needs of consumer protection, coupled with the new regulations and environmental concerns, require the development of more eco-friendly flame-retardant treatments for PP fibers. Improvements in flame retardancy of the fiber-forming polymers, including PP, have become increasingly important in recent years, to comply with the safety requirements of textile products for automotive and home furnishing [2]. Flammability of PP fibers represents one of the main drawbacks for the use of this polymer, due to its aliphatic hydrocarbon structure. This combustible material ignites spontaneously and can be ignited at about 360 and $345^{\circ} \mathrm{C}$, respectively. Since the burning leads to the formation of droplets spreading the fire, the reduction of flammability of PP is needed for safety consideration. Furthermore, polypropylene has a high heat of combustion, about $46.4 \mathrm{~kJ} \cdot \mathrm{g}^{-1}$, and no char-forming character with a limiting oxygen index (LOI) of about $18 \%$. Its ignition time is relatively low compared with some other thermoplastics, and even if it may be classified as a polymer with low smoke emission, its high peak of heat release and its rapid production of smoke constitute a hazard in real fire situations. To prevent the burning and to enhance the fire retardant (FR) properties of textile structures, various solutions have been studied. One of them introduces a single additive or a mixture of additives to provide a synergistic effect and/or to reduce cost, into the polymer by melt mixing processes or onto the surface by finishing treatments. One way recognized to develop effective intumescent systems is the use of metal hydroxides such as magnesium and aluminum. Nevertheless, a high amount of additive is required, about $60 \mathrm{wt} \%$ and $25 \mathrm{wt} \%$ to $30 \mathrm{wt} \%$ for single or mixture of FR, respectively [3]. This loading content is not suitable to manufacture fiber with conventional textile processes, since the addition of such a high content of additive into the fibers decreases their mechanical properties, which limits their use in conventional spinning textile process. The use of high loadings of additives can be only achieved by surface coating processes, which can impair properties of the substrate such as softness, drapability, etc. Typically, the amount of additives within a fiber should not exceed $10 \mathrm{wt} \%$ and more generally should be restricted to $5 \mathrm{wt} \%$ or $6 \mathrm{wt} \%$ for a flame retardant polypropylene fiber produced by melt-spinning. Furthermore, the additives have to be thermally stable during the manufacturing process and compatible with the polymer matrix. They should have particle sizes that will not affect the fiber spinning process, they should not change the color of the final substrate, and should have no leaching properties. Furthermore, they should retain their flame retardant properties after textile processing. They should function at a lower temperature than the degradation temperature of the PP and should reduce the toxicity of gases and smoke produced during burning to an acceptable level. 
Bourbigot et al. reviewed several solutions for flame retarding textile structures [4]. For the PP fabrics, these solutions were mainly based on nano-additives and carbon nanotubes, but their efficiencies were limited, even if good results were obtained by cone calorimeter study. Furthermore, the use of carbon nanotubes leads to a black fiber. Zhang et al. obtained an increase in FR performance by adding $6 \mathrm{wt} \%$ of a mixture of clay (Cloisite ${ }^{\circledR} 30 \mathrm{~B}$, Southern Clay Products, Inc., Gonzales, TX, USA), ammonium polyphosphate and a sterically-hindered amine [2]. Despite these results, the low thermal stability and the relatively high particle size of ammonium polyphosphate restrict its use for spinning. One current solution is the use of halogenated products in the core of the fibers. For example, the product@2spin PP2017M (Devan Chemicals, Ronse, Belgium) achieves an M1 rating for a PP nonwoven with only $3 \mathrm{wt} \%$ of additives. The last decade has witnessed a desire to reduce the impact of flame retardants generally on the eco-system and much research has moved towards halogen-free systems and/or their combination with lower amounts of halogen to allow substantial decreases in the halogenated substances present to occur [5]. Another possibility is the synthesis or the formulation of multifunctional flame retardants, such as Flamestab ${ }^{\circledR}$ Nor 116 (BASF, Basel, Switzerland) which is mainly used for polypropylene fibers or films [6]. In this context, Roth and coworkers have developed new nitrogen based flame retardant compounds that exhibit self-extinguishing properties for polypropylene compounds [5,7-9].

Recently announced mixtures of phosphinates and other phosphorus compounds [10-14] have enabled Devan to develop for PP a novel flame retardant masterbatch. The aim of this article is to present the main results obtained by using this new mixture of phosphinates (MPh), in combination with classical nitrogen synergist agent, melamine cyanurate (MC), in different polypropylene textile structures. All the studies were made with a total amount of $6 \mathrm{wt} \%$ of FR additives. In the first part, the impact of two kinds of textile structures with a chosen ratio of the both FR additives in the combination was investigated. In the second part, the influence of the ratio between the melamine cyanurate (MC) and a mixture of phosphinate $(\mathrm{MPh})$ for a nonwoven support was investigated. The influence of FR additives on the thermal properties and stability of the PP fibers were investigated by DSC (Differential scanning calorimetry) and TGA (Thermogravimetric analysis), and the estimation of fire behavior of the textile fabrics by cone calorimeter and limiting oxygen index (LOI) measurements are discussed. Furthermore, two other standard tests for industrial applications, i.e., DIN 4102-1 part B [15] and FMVSS 302 [16] are used to determine the potential of the use of these new additives in textiles for automotive and building applications.

\section{Experimental Section}

\subsection{Materials}

A commercial grade of isotactic polypropylene (iPP), Borealis HG420 FB (Borealis AG, Vienna, Austria), with a Melt Flow Index of $25 \mathrm{~g} \cdot 10 \mathrm{~min}^{-1}$ ) was used as the matrix. A melamine cyanurate (MC) and a mixture of phosphinate ( $\mathrm{MPh}$ ) (white powder of an inorganic aluminum phosphinates mixed with phosphate ester in about a 85:15 weight ratio, phosphorus content about $30 \%$, degradation temperature at $5 \%$ of weight loss above $300{ }^{\circ} \mathrm{C}$ ) supplied by Devan Chemicals (Ronse, Belgium) were used to develop the flame retardant system. The supplier discloses nitrogen content of about $48 \%$ and a 
medium particle size about 2-3 $\mu \mathrm{m}$ for the $\mathrm{MC}$ whereas the exact composition of $\mathrm{MPh}$ is kept confidential. The thermal stability of each additive was checked by TGA to confirm stability at the temperature of the spinning process.

\subsection{Preparation of the iPP Multifilaments}

Two masterbatches were prepared by melt extrusion using a co-rotating, intermeshing twin-screw extruder Thermo Haake (Thermo Fisher Scientic, Waltham, MA, USA), with a screw diameter of $16 \mathrm{~mm}$ and a Length to Diameter Ratio of 25 under conditions that permit the formation of a micro material. Prior to compounding, $60 \mathrm{wt} \%$ of polymer pellets with $40 \mathrm{wt} \%$ of $\mathrm{MC}$ or $\mathrm{MPh}$ were first hand-mixed by shaking them in a plastic container. For the production of these masterbatches, the temperature of the five heating zones were at 110,170, 200, 200 and $200{ }^{\circ} \mathrm{C}$ respectively; the screw speed was set at $150 \mathrm{rpm}$. The extrudate obtained was transformed into a pellet form to be processed afterwards as multifilament yarns.

Continuous virgin or FR-loaded iPP-multifilament yarns were made via a spinning process using a Spinboy I melt spinning machine (Busschaert engineering, Deerlijk, Belgium) (Figure 1, Table 1). In the case of FR sample, virgin iPP pellets and the masterbatches were fed into the single-screw extrusion and spinning apparatus to reach a loading content of the FR component of about $6 \mathrm{wt} \%$. The heating along the screw was adjusted to obtain a temperature gradient from 220 to $230{ }^{\circ} \mathrm{C}$. A volumetric pump regulated the injection of molten polymer towards the dies at a flow rate of $100 \mathrm{~cm}^{3}$ per minute. The filaments were air cooled and then drawn by means of two heated rolls, at 70 and $80^{\circ} \mathrm{C}$, respectively, before being wound. Spin finish was applied on the filaments before their passage in the drawing rolls. The speeds of the two rolls served to adjust the drawing ratio: the first roll speed was set at $200 \mathrm{rpm}$, whereas the second one was set at $600 \mathrm{rpm}$, giving a theoretical drawing ratio of 3 . The final winding speed was the same as the second draw roll. The multifilament yarns obtained consisted of 80 circular continuous filaments with an overall linear density of approximately 1500 dTex $\left(1 \mathrm{Tex}=1 \mathrm{~g} \cdot \mathrm{km}^{-1}\right)$.

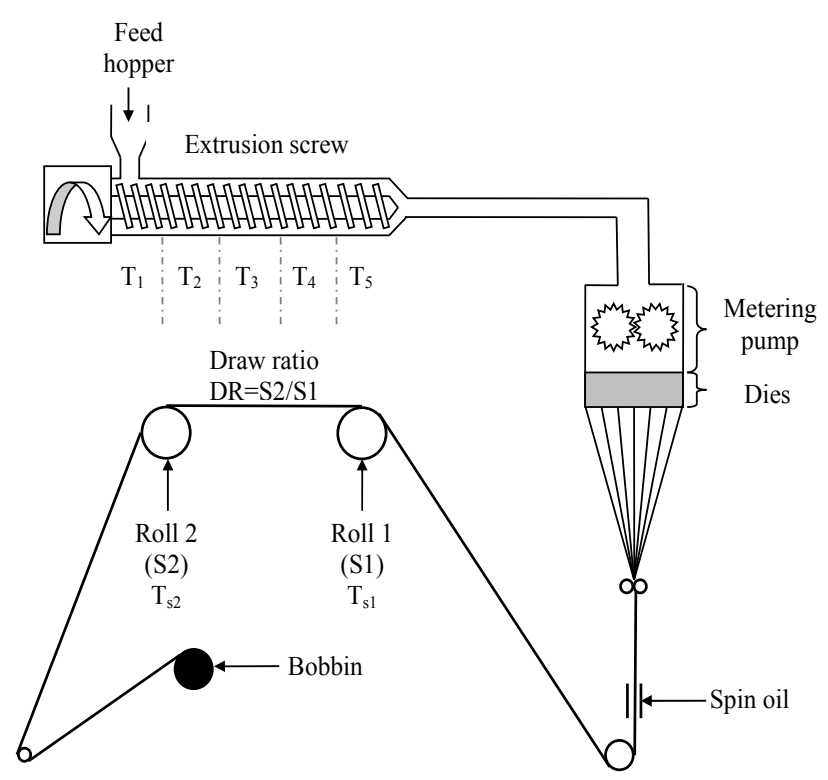

Figure 1. Principle of the melt-spinning machine. 
Table 1. Composition of the multifilaments used in this study.

\begin{tabular}{cccc}
\hline Sample Label & $\mathbf{i P P}(\mathbf{w t} \%)$ & $\mathbf{M C}(\mathbf{w t} \%)$ & $\mathbf{M P h}(\mathbf{w t} \%)$ \\
\hline $\mathrm{mf}_{1}$ & 100.0 & - & - \\
$\mathrm{mf}_{2}$ & 94.0 & 6.0 & - \\
$\mathrm{mf}_{3}$ & 94.0 & 3.0 & 3.0 \\
$\mathrm{mf}_{4}$ & 94.0 & 2.0 & 4.0 \\
$\mathrm{mf}_{5}$ & 94.0 & 1.5 & 4.5 \\
\hline
\end{tabular}

\subsection{Preparation of the Nonwovens Fabrics}

For each sample, $200 \mathrm{~g}$ of crimped fibers, hand-cut to $50 \mathrm{~mm}$ length, were introduced into a roller-carding machine (Monteleone Group - Nuova Cosmatex, Benna, Italy) to obtain a first fibrous web. To optimize the homogeneity of the web, this pre-formed fabric was rotated through $90^{\circ}$ and fed once again into the card. At this step, the web was layered more or less, which leads to samples with different basis weights. Finally, the fabric structure which has undergone two carding operations, was needle-punched in order to obtain a consolidated product with a basis weight of $200 \mathrm{or} 290 \mathrm{~g} \cdot \mathrm{m}^{-2}$.

\subsection{Preparation of the Knitted Fabrics}

Multifilament yarns were knitted on flat hand knitting machines (Dubied, Couvet, Switzerland). A thin jersey fabric (thickness about $0.8 \mathrm{~mm}$ and a fabric weight of $110 \mathrm{~g} \cdot \mathrm{m}^{-2}$ ) and a thicker rib-based fabric (thickness about $4.8 \mathrm{~mm}$ and a fabric weight of $380 \mathrm{~g} \cdot \mathrm{m}^{-2}$ ) were produced on a E12-gauge machine using a single multifilament yarn and on a E5-gauge machine when four multifilament yarns were co-fed into the knitting machine, respectively.

Physical properties of the different textile structures such as thickness and basis weight are reported in the Table 2. Five thickness measurements have been performed randomly on a sample using a pressing plate with a pressure of $0.1 \mathrm{KPa}$ to determine an average thickness following the standard ISO 5084 [17]. This sample has then been weighted using a balance with an accuracy of $10^{-3} \mathrm{~g}$ in order to determine the mass per unit area following the standard ISO 3801 [18].

Table 2. Characteristics of the PP textile structures.

\begin{tabular}{ccc}
\hline Sample & Basis Weight $\left(\mathbf{g} \cdot \mathbf{m}^{-\mathbf{2}}\right)$ & Thickness (mm) \\
\hline Nonwoven & 200 & 2.2 \\
Nonwoven & 290 & 2.8 \\
Thin knitted sample (Jersey) & 110 & 0.8 \\
Thick knitted sample (Rib) & 380 & 4.8 \\
\hline
\end{tabular}

\subsection{Characterization}

\subsubsection{Thermal Properties of iPP Multi-Filaments-DSC Analysis}

The thermal behavior of the fabric samples was recorded using a Setaram DSC 92 thermal analysis instrument (Setaram Instrumentation, Caluire, France) operated via control software on a PC. Indium, zinc, bismuth and lead were used to calibrate the DSC and the analysis was made under a constant 
stream of nitrogen $\left(50 \mathrm{~mL} \cdot \mathrm{min}^{-1}\right)$. Samples were placed in aluminum pans, which were hermetically sealed before being placed on the calorimeter thermocouples. The sample space was purged with nitrogen at a constant flow $\left(50 \mathrm{~mL} \cdot \mathrm{min}^{-1}\right)$ during the experiments and the temperature range was increased from -30 to $250{ }^{\circ} \mathrm{C}$ at $10{ }^{\circ} \mathrm{C} \cdot \mathrm{min}^{-1}$. In order to erase any previous thermal history in the material, the scanning procedure involved an initial heating from -30 to $250{ }^{\circ} \mathrm{C}$ at a rate of $10{ }^{\circ} \mathrm{C} \cdot \mathrm{min}^{-1}$, followed by an isothermal stop at $250{ }^{\circ} \mathrm{C}$ for $10 \mathrm{~min}$. The sample was then cooled at a rate of $10{ }^{\circ} \mathrm{C} \cdot \mathrm{min}^{-1}$, before repeating the temperature scan from -30 to $250{ }^{\circ} \mathrm{C}$ at $10{ }^{\circ} \mathrm{C} \cdot \mathrm{min}^{-1}$ during which the melting endotherm and the crystallization exotherm of the sample were recorded. The crystallinity index of sample $\left(X_{\mathrm{c}}\right)$ was calculated according to Equation (1):

$$
X_{\mathrm{c}}=\frac{\Delta H_{\mathrm{m}}}{\Delta H_{\mathrm{m}}^{0}\left(1-w_{\mathrm{m}}\right)} \times 100
$$

where, $\Delta H_{\mathrm{m}}$ is the specific melting heat, $\Delta H_{\mathrm{m}}$ is the theoretical specific melting heat of $100 \%$ crystalline isotactic PP, at $207 \mathrm{~J} \cdot \mathrm{g}^{-1}$, and $w_{\mathrm{m}}$ is the weight fraction of FR [19].

\subsubsection{Thermogravimetric Analysis of iPP Fibers}

The thermogravimetric analysis (TGA) was carried out on a TA 2050 instrument (TA Instruments, New Castle, DE, USA) under nitrogen atmosphere at a purge rate of $50 \mathrm{~mL} \cdot \mathrm{min}^{-1}$. For each experiment, a sample of approximately $10 \mathrm{mg}$ was used. A heating rate of $10{ }^{\circ} \mathrm{C} \cdot \mathrm{min}^{-1}$ was applied, and the temperature was raised from 20 to $600{ }^{\circ} \mathrm{C}$.

\subsubsection{Fire Properties of Textile Substrates}

The flame retardant properties of fabric samples were measured using a cone calorimeter according to ISO 5660 [20] and EN 45545-2 [21]. Specimens (plates $100 \times 100 \times 3 \mathrm{~mm}^{3}$ ) were exposed to an external heat flux of $25 \mathrm{~kW} \cdot \mathrm{m}^{-2}$. Data on principal fire reaction characteristics were obtained: time to ignition (tign), peak of heat release rate (PHRR), and total heat released (THR) and total smokes volume (TSV). From heat release rate (HRR) values, the average rate of heat emission (ARHE) defined in Equation (2) and its maximum (MARHE) were calculated. The data reported in this paper are the average of two replicated experiments:

$$
\operatorname{ARHE}\left(t_{n}\right)=\frac{\sum_{2}^{n}\left(\left(t_{n}-t_{n-1}\right) \times \frac{q_{n}+q_{n-1}}{2}\right)}{t_{n}-t_{0}}
$$

where, $t_{n}$ and $q_{n}$ are the time and rate of heat release at $t_{n}$, respectively.

The flame retardant (FR) performance was evaluated by three normalized tests that are classically used for textiles. FMVSS 302 [16] is a standard for automotive applications, employing a horizontal test specimen [22]. The rate of spread flame was determined over measured length, to pass the test the maximum permitted rate of flame spread should not exceed $101.6 \mathrm{~mm} / \mathrm{min}$. In the DIN 4102-1 [15] there is different class associated to different requirements, (B1) low flammability, (B2) moderately flammable and (B3) highly flammable. One of the aims of this study was to check if the textile structures achieved class B2 (vertical test). To pass, the sample is subjected to edge and/or surface exposure from a gas flame, and the flames should not reach the top marking within $20 \mathrm{~s}$. NF P92-503 [23] 
was also used to classify the specimens. In this test, a sample is placed in a specimen holder at $30^{\circ}$ above a radiator which gives out heat. A small butane flame is directly applied to the nonwoven surface, and the flame duration, the burning droplets production, as well as the length/width of the damaged sample were recorded.

\section{Results and Discussion}

\subsection{Selection of the Textile Substrate}

Table 3 shows the flame retardant performance of the four kinds of textile structures investigated in this study. All the samples were prepared from the $\mathrm{mf}_{5}$ fibers. According to the textile structure, the results are different, this can be related to sample thickness as well as its physical structure, as underlined by Kandola and Kandare [24]. From the FMVSS 302 test [16], all the samples did not ignite, except for the nonwoven of $290 \mathrm{~g} \cdot \mathrm{m}^{-2}$ with a rate of flame spread of $89 \mathrm{~mm} / \mathrm{min}$. For these three textile structures, the substrate fled the heat flow, when the flames progressed along it, until no fuel was available to maintain combustion. The nonwoven sample with a basis weight of $290 \mathrm{~g} \cdot \mathrm{m}^{-2}$ was an exception, since this compact structure could not flee the flame which slowly progressed on the surface.

Table 3. Flame retardant performances of textiles samples.

\begin{tabular}{cccc}
\hline Sample label & FMVSS 302 & DIN 4102-1 & NFP 92 503 \\
\hline Nonwoven $\left(200 \mathrm{~g} \cdot \mathrm{m}^{-2}\right)$ & Did not ignite & Pass B2 & No rating \\
Nonwoven $\left(290 \mathrm{~g} \cdot \mathrm{m}^{-2}\right)$ & $89 \mathrm{~mm} /$ min & Pass B2 & No rating \\
Jersey $\left(110 \mathrm{~g} \cdot \mathrm{m}^{-2}\right)$ & Did not ignite & Pass B2 & M1 \\
Knitted sample $\left(380 \mathrm{~g} \cdot \mathrm{m}^{-2}\right)$ & Did not ignite & No rating & No rating \\
\hline
\end{tabular}

For the DIN 4102-1 [15], the thick knitted sample was the only one that failed the DIN 4102-1 test. There were some droplets and the polymer was molten. The jersey fabric gave the best performance with success in all the tests. This was the only sample that reached the M1 specification of the French standard. One of the reasons was its characteristics (thickness, lightness). When placed above the radiant source, the structure opened significantly and no polymer remained for burning when the flame progressed along the sample length. The sample passed the NF P92-504 [25] vertical-test method without difficulty. The performance decreased with the increase of sample thickness. Thus, there is more fuel for burning, and the diffusion of the heat is different from the case of an opened structure fabric. The thin sample fled the heat flux, the distance between the material and the flame increased, so the temperature at the surface decreased, and finally, the FR additives were efficient to protect the support. For the thick samples, the heat and the flame were continuously in contact with the support. For test methods using a horizontal test specimen and, more particularly, the FMVSS 302 standard [16], the only substrate that did not ignite was the nonwoven fabric of $290 \mathrm{~g} \cdot \mathrm{m}^{-2}$. The others substrates had different behaviors; the jersey and the nonwoven opened their structures when the flame approached, such that there was no material available for burning. The thick knitted sample cannot open due to the thickness and the structure, so the polymer melts and carbonizes at the point of flame contact, without flame propagation. These behaviors have also been observed during the DIN test and, as shown in Figure 2, the border of the nonwoven was carbonized with an increase of the distance between the 
flame source and the edge of the hole. The behavior of the jersey was similar. During the test, the thick knitted sample could not open due to its thickness and its basis weight, and thus was maintained in contact with the flame. As the polymer started to carbonize, the surface, due the amount of material, melted and produced droplets. The FR formulation was not efficient enough for this type of evaluation. Based on the performance and behavior of the different supports and taking into account industrial considerations, the influence of the ratio MPh to MC was studied with a nonwoven having a basis weight of $290 \mathrm{~g} \cdot \mathrm{m}^{-2}$.

\section{After the FMVSS test}

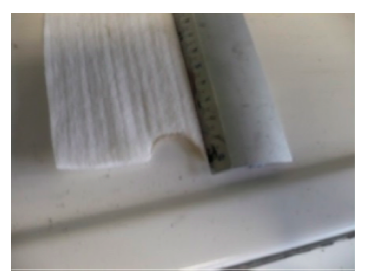

$\mathrm{mf} 3$

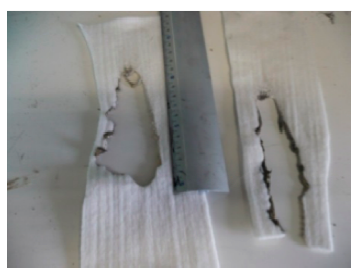

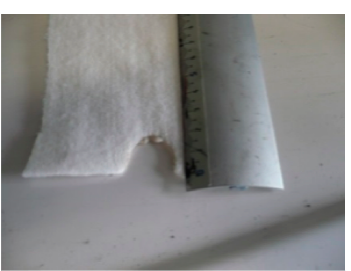

$\mathrm{mf}_{4}$

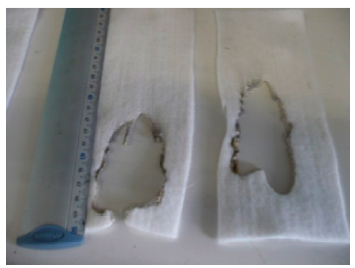

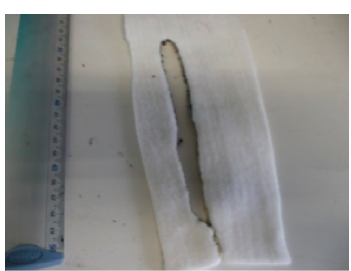

$\mathrm{mf} 5$

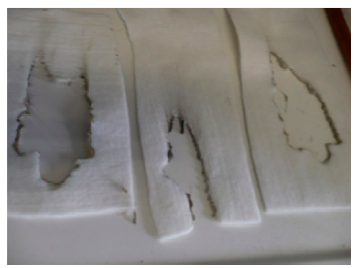

\section{After the DIN 402 test}

Figure 2. Images of the FMVSS and DIN 402 exposed samples.

\subsection{Thermal Properties of Neat and FR-Loaded iPP Fibers}

Incorporating FR additives in PP leads to a modification of its morphology and thermal stability, and can affect its rheological behaviors and therefore its spinnability. Table 4 presents the thermal properties of nonwovens realized from various FR formulations.

Table 4. Thermal properties of nonwovens studied on this study.

\begin{tabular}{cccccccc}
\hline Sample Label & $\boldsymbol{T}_{\mathbf{m}}$ Onset $\left({ }^{\circ} \mathbf{C}\right)$ & $\boldsymbol{T}_{\mathbf{m}}$ Peak $\left({ }^{\circ} \mathbf{C}\right)$ & $\boldsymbol{\Delta} \boldsymbol{H}_{\mathbf{m}}(\mathbf{J} / \mathbf{g})$ & $\boldsymbol{T}_{\mathbf{c}}$ Onset $\left({ }^{\circ} \mathbf{C}\right)$ & $\boldsymbol{T}_{\mathbf{c}}$ Peak $\left({ }^{\circ} \mathbf{C}\right)$ & $\boldsymbol{\Delta} \boldsymbol{H}_{\mathbf{c}}(\mathbf{J} / \mathbf{g})$ & $\boldsymbol{X}_{\mathbf{c}}(\%)$ \\
\hline $\mathrm{mf}_{1}$ & 146.0 & $150-166$ & 82 & 116.1 & 110.0 & 86 & 39.6 \\
$\mathrm{mf}_{2}$ & 160.1 & 167 & 79 & 122.2 & 118.5 & 99 & 40.6 \\
$\mathrm{mf}_{3}$ & 159.3 & 166 & 90 & 122.4 & 118.2 & 94 & 46.3 \\
$\mathrm{mf}_{4}$ & 159.1 & 166 & 97 & 122.5 & 118.3 & 101 & 49.9 \\
$\mathrm{mf}_{5}$ & 159.5 & 166 & 92 & 122.0 & 118.4 & 96 & 47.3 \\
\hline
\end{tabular}

Notes: $T_{\mathrm{m}}$ onset: onset temperature of the melting peak; $T_{\mathrm{m}}$ peak: temperature of the sample at the point of maximum rate of melting; $\Delta H_{\mathrm{m}}$ : melting enthalpy of the sample; $T_{\mathrm{c}}$ onset: onset temperature of the crystallization peak; $T_{\mathrm{c}}$ peak: temperature of the sample at the point of maximum rate of crystallization; $\Delta H_{\mathrm{c}}$; crystallization enthalpy of the sample. 
The thermal properties of the iPP composite fibers were evaluated by subjecting the samples to a temperature ramp cycle at a rate of $10{ }^{\circ} \mathrm{C} \cdot \mathrm{min}^{-1}$. In absence of flame retardant, the mf 1 sample presented two melting peaks at 150 and $166^{\circ} \mathrm{C}$, whereas for the loaded samples, only one peak at $166{ }^{\circ} \mathrm{C}$ was detected. The lowest melting peak is ascribed to the melting of the $\beta$-phase $\left(150{ }^{\circ} \mathrm{C}\right)$, and may be due to the presence of additives in the raw PP, whereas the highest temperature relates to the melting of the $\alpha$-phase. The absence of this $\beta$-phase in the four other samples may result to the beta to alpha phase transition which can occur during the thermal treatment and spinning process [26,27]. The effect of the additives formulation on the relative crystallinity is shown in Table 4. It is seen that the presence of the FR increases the crystallinity, which can be a consequence of a higher local crystallinity at the matrix-FR interface as underlined by Misra and coworkers [28,29]. Furthermore, this effect may be related to ratio $\mathrm{MPh}$ to $\mathrm{MC}$, and was greater for a ratio value about 2 to 1 . The maximum rate of crystallization occurs at $116.1{ }^{\circ} \mathrm{C}$ for neat isotactic polypropylene fibers $\left(\mathrm{mf}_{1}\right)$, and increases by $6{ }^{\circ} \mathrm{C}$ with the presence of the FR additives. Therefore, all the blends can act as an effective nucleating agent for iPP matrix.

\subsection{Thermal Stability of Nonwoven Fabrics}

The effect of the FR additives on the thermal stability of the fibers of the nonwoven fabrics was studied by means of thermogravimetric experiments carried out in inert conditions at $10{ }^{\circ} \mathrm{C} \cdot \mathrm{min}^{-1}$. From Figure 3, the thermal behavior of $\mathrm{mf}_{1}$ displayed single step degradation. The decomposition of this sample, characterized by the onset temperature at $5 \%$ weight loss, started at $375{ }^{\circ} \mathrm{C}$. The main decomposition peak relating to the iPP backbone decomposition took place at $466{ }^{\circ} \mathrm{C}$, and the maximum rate of decomposition was fast $\left(15.1 \% \cdot \mathrm{min}^{-1}\right)$. Furthermore, there is no char residue remaining at over $510{ }^{\circ} \mathrm{C}$. According to the type of FR formulations, the weight loss of nonwoven fabrics started either at higher temperature for $\mathrm{mf}_{2}\left(390{ }^{\circ} \mathrm{C}\right), \mathrm{mf}_{4}\left(383{ }^{\circ} \mathrm{C}\right)$ and $\mathrm{mf}_{5}\left(383{ }^{\circ} \mathrm{C}\right)$, or at $376{ }^{\circ} \mathrm{C}$ for $\mathrm{mf}_{3}$ which is almost the same to the $T_{\text {onset }}$ of $\mathrm{mf}_{1}$, suggesting that the thermal stability of nonwoven was not enhanced for this last sample. Furthermore, from the DSC analysis it was observed that the presence of additives has effect on the fiber structure, thus the thermal degradation process should be different. From the TG and DTG (Differential thermal gravity) curves (Figure 3), it can be seen that the nonwoven fibers loaded with FR additives displayed double step degradation process. The first stage was in the range of $280-400{ }^{\circ} \mathrm{C}$ with a low weight loss about $7 \%$, and in which these samples present a peak rather than the shoulder of the $\mathrm{mf}_{1}$ sample. The second stage occurred from 400 to $500{ }^{\circ} \mathrm{C}$. All the samples have a sharper peak than $\mathrm{mf}_{1}$, with a highest decomposition rate. The maximum weight loss points were found between 473 and $480{ }^{\circ} \mathrm{C}$, relatively higher than $\mathrm{mf}$ and the raw sample. No residues were observed above $500{ }^{\circ} \mathrm{C}$. These results suggest that the degradation of the additives starts before the iPP one to stabilize the matrix or slow down the degradation. Under inert atmosphere, the iPP degradation is related to a chain scission mechanism [30]. The presence of the FR additives, and more specially the melamine, can act as radical scavengers [31,32]. As observed with the increase in temperature, the rate of degradation increases too, therefore the MC was no longer effective in this temperature range. 


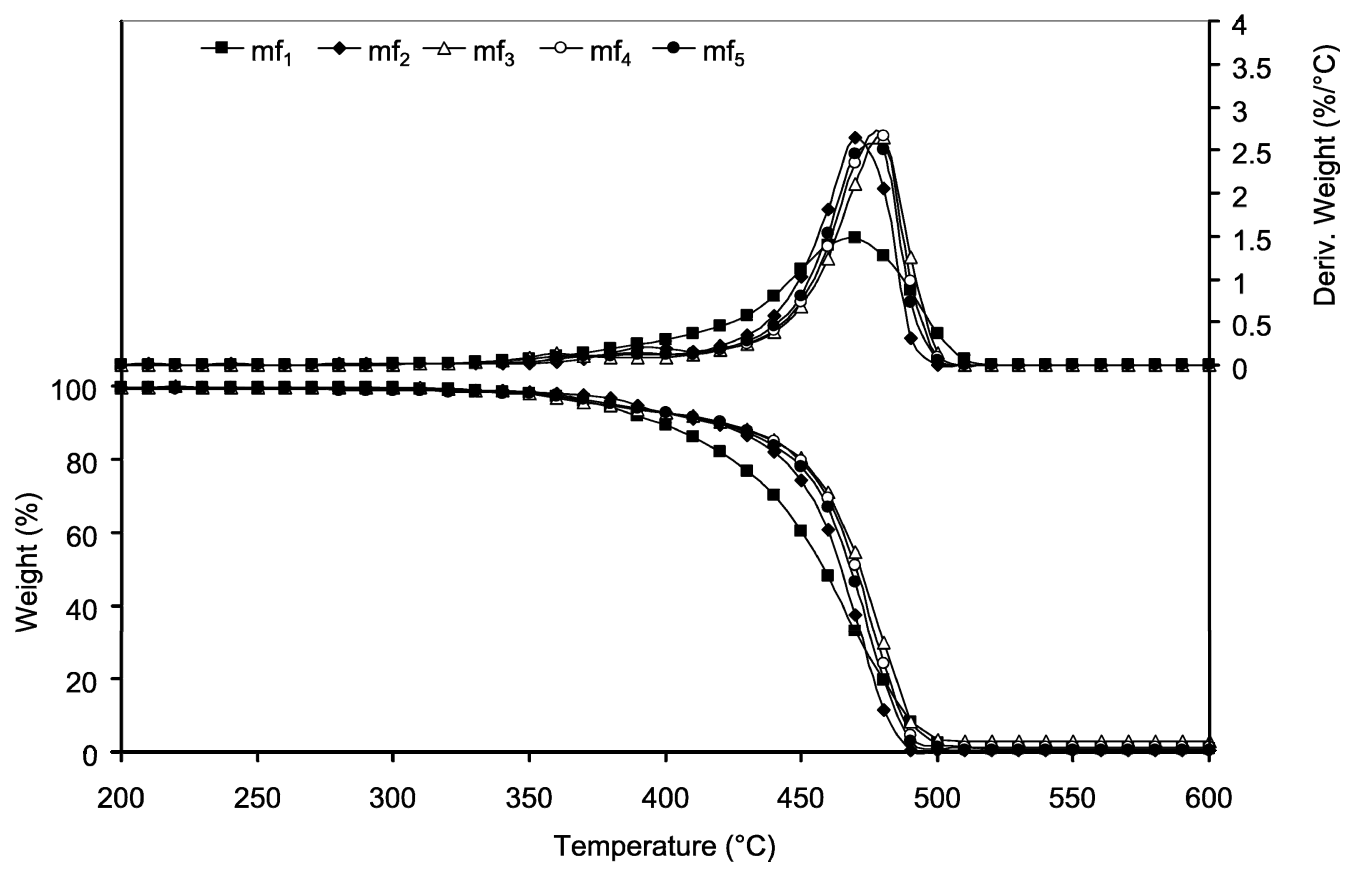

Figure 3. TG and DTG curves of loaded iPP fibers in inert atmosphere with a heating rate of $10^{\circ} \mathrm{C} \cdot \mathrm{min}^{-1}$.

\subsection{Flame Retardancy of Nonwoven Fabrics}

Table 5 presents the changes of LOI values according to FR additive formulations at a concentration about $6 \mathrm{wt} \%$. It can be seen that the LOI values of the loaded samples are higher than $\mathrm{mf}_{1}$, and reaches the maximum of $24.9 \%$ for the sample $\mathrm{mf}_{3}$. These low LOI values compared to other flame retardant formulations may be related to the FR loading content in PP composites, i.e., $6 \mathrm{wt} \%$. LOI values higher than 30 may be reached with FR formulations at least $18 \mathrm{wt} \%$ of loading level in PP, but these loading contents are too high for fiber applications [32]. Furthermore, it seems that the values are not correlated to the ratio of $\mathrm{MPh}$ to $\mathrm{MC}$, since it increases with the addition of $\mathrm{MC}$ and decreases when the ratio is higher than 1 , but is still higher than the sample with only MC. The LOI test results indicate that there is an optimum ratio of additive where an obvious effect exists between $\mathrm{MPh}$ and $\mathrm{MC}$, and the higher loading of $\mathrm{MPh}$ restrains the flame retardancy behavior of the system and decreases the value of LOI. These results illustrate that the presence of the nitrogen from melamine cyanurate enhances the flame retardant effect of the phosphorus flame-retardant compound.

Table 5. LOI performances of nonwoven samples.

\begin{tabular}{cc}
\hline Sample label & LOI $\left(\mathbf{O}_{2}\right.$ vol\%) \\
\hline $\mathrm{mf}_{1}$ & $17.9 \pm 0.5$ \\
$\mathrm{mf}_{2}$ & $23.1 \pm 0.5$ \\
$\mathrm{mf}_{3}$ & $24.9 \pm 0.5$ \\
$\mathrm{mf}_{4}$ & $24.3 \pm 0.5$ \\
$\mathrm{mf}_{5}$ & $24.0 \pm 0.5$ \\
\hline
\end{tabular}

Heat release rate (HRR) can be considered as an important parameter for studying flammability behavior. An effective flame retardant system should show low values of peak and average of HRR 
and therefore lowest MAHRE (Maximum Average Rate of Heat Emission). Figure 4 presents the HRR curves of various samples at a heat flux of $25 \mathrm{~kW} \cdot \mathrm{m}^{-2}$. It can be observed that $\mathrm{mf}_{1}$ sample burnt out within $70 \mathrm{~s}$ after ignition and reached a maximum HRR value of $365 \mathrm{~kW} \cdot \mathrm{m}^{-2}$ at $70 \mathrm{~s}$. With the presence of $\mathrm{MC}\left(\mathrm{mf}_{2}\right)$, the peak heat release rate is reduced of $21 \%$, whereas the ignition time was increased of $23 \mathrm{~s}$ (Table 6). The effect of melamine cyanurate in flame retardancy is related to its endothermic decomposition, and the release of nonflammable ammonia attributed to the condensation of the melamine to promote the formation of cyameluric structure above $400{ }^{\circ} \mathrm{C}[33,34]$. The presence of MC delays the ignition time by creating a heat sink during the first stage of its degradation. When $\mathrm{MPh}$ additive is introduced with $\mathrm{MC}$ (samples $\mathrm{mf}_{3}$ to $\mathrm{mf}_{5}$ ), the ignition time value is comprised between the raw sample and $\mathrm{mf}_{2}$, and at high ratio value tends to the $\mathrm{mf}_{2}$ one. The increase of ignition time may result from the fuel dilution of MC [35]. The influence of MPh on the HRR is limited for the samples $\mathrm{mf}_{3}$ and $\mathrm{mf}_{4}$, since the decrease of peak of heat release rate is close to $\mathrm{mf}_{2}$ one, whereas for a ratio of 3/1 (sample $\mathrm{mf} 5$ ) a higher variation of $30 \%$ was detected. According to the HRR results, it can be determined that by increasing the proportion of $\mathrm{MPh}$ and so the phosphorus content, the peak value of HRR is decreasing which does not match with the LOI results. Furthermore, the presence of the FR additives allows decreasing significantly the THR and MAHRE values.

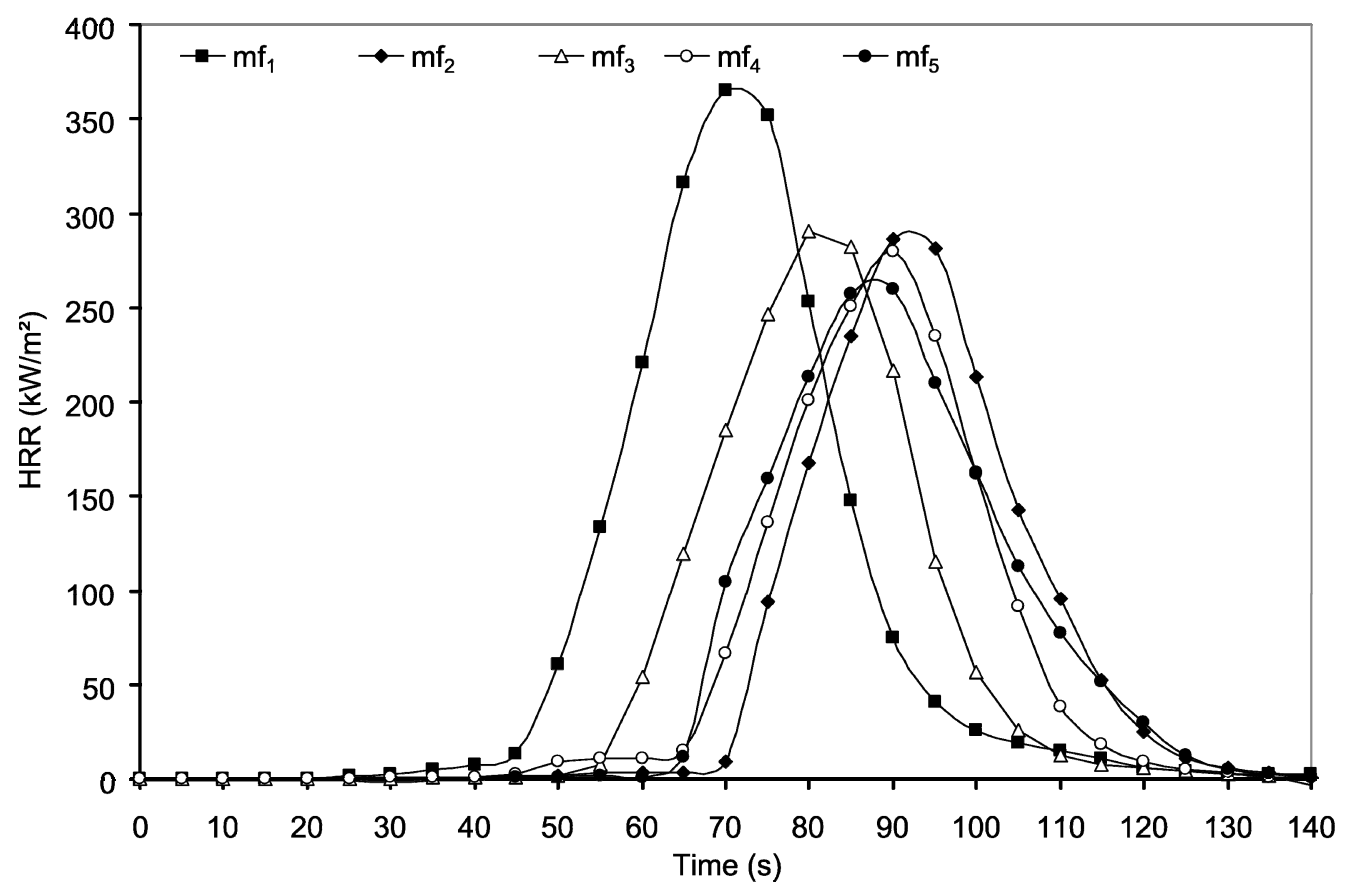

Figure 4. Heat release rate of the nonwoven samples.

Table 6. Cone calorimeter parameters for the different PP nonwoven samples.

\begin{tabular}{cccc}
\hline Sample label & Ignition Time (s) & THR $\left(\mathbf{M J} / \mathbf{m}^{2}\right)$ & MAHRE $(\mathbf{k W} / \mathbf{m} \cdot \mathbf{s})$ \\
\hline $\mathrm{mf}_{1}$ & $42 \pm 2$ & 10.4 & 106.0 \\
$\mathrm{mf}_{2}$ & $65 \pm 2$ & 9.0 & 72.2 \\
$\mathrm{mf}_{3}$ & $52 \pm 2$ & 8.1 & 84.5 \\
$\mathrm{mf}_{4}$ & $62 \pm 2$ & 7.8 & 67.8 \\
$\mathrm{mf}_{5}$ & $61 \pm 2$ & 8.1 & 69.5 \\
\hline
\end{tabular}


With the highest ignition time, the lowest MAHRE and an important decrease in the THR, the samples $\mathrm{mf}_{2}, \mathrm{mf}_{4}$ and $\mathrm{mf}_{5}$ seemed to be similar and gave the best results, which corresponds to the addition of pure $\mathrm{MC}$ or its replacement with a mixture of $\mathrm{MPh} / \mathrm{MC}$ with a ratio 2/1 and 3/1. Considering the LOI values, and the cone calorimeter, all the formulations brought flame retardant properties to the PP. Replacing a part of MC by MPh did not impaired the performances. The potential of $\mathrm{MPh}$ and $\mathrm{MC}$ combination as a new formulation for polypropylene nonwoven was investigated by performing ignitability tests in accordance to FMVSS 302 [16], DIN 4102-1 (class B) [15] and NF P92-503 [22] standards (Table 7). With the different formulations, no sample was able to realize successfully all the norms. There was no difference between the formulation $\mathrm{mf}_{2}$ and the virgin PP, so it can be concluded that $\mathrm{MC}$ alone has no effect to stop the flame spread, although the contribution to fire (HRR) of PP with MC is lower than virgin PP.

Table 7. Ranking of the samples according FMVSS 302, DIN 4102-1 and NFP 92,503 tests.

\begin{tabular}{cccc}
\hline Sample label & FMVSS 302 & DIN 4102-1 & NFP 92 503 \\
\hline $\mathrm{mf}_{1}$ & $>101.6 \mathrm{~mm} \cdot \mathrm{min}^{-1}$ & No rating & No rating \\
$\mathrm{mf}_{2}$ & $>101.6 \mathrm{~mm} \cdot \mathrm{min}^{-1}$ & No rating & No rating \\
$\mathrm{mf}_{3}$ & Did not ignite & Pass B2 & No rating \\
$\mathrm{mf}_{4}$ & Did not ignite & Pass B2 & M4 \\
$\mathrm{mf}_{5}$ & $89 \mathrm{~mm} \cdot \mathrm{min}^{-1}$ & Pass B2 & No rating \\
\hline
\end{tabular}

According to the FMVSS 302 test [16], formulations $\mathrm{mf}_{3}$ and $\mathrm{mf}_{4}$ showed the best performance with absolutely no flame propagation as shown in Figure 2. The formulation $\mathrm{mf}_{5}$ had a strange behavior with a flame progression seen as a small path without side propagation. The propagation was very low. The samples $\mathrm{mf}_{1}$ and $\mathrm{mf}_{2}$ were completely burned. The structure opened and some dripping occurred, but the flame did not ignite the cotton fibers and there was no propagation. For the different samples, the border of the damage zone looked black, but it was not a char. Furthermore, the flame propagation was different for the samples when ignited on the edge or on the surface as seen in the Figure 2. The flame propagation was vertical in the test whereas on the surface of the sample, the flame propagated in both directions before extinction. This behavior was not classical. Indeed, an opening of light PP nonwovens or films generally occurred with other non-halogenated treatments. This was probably due to the thickness of our samples. In the end, the most important result is that the formulations combining $\mathrm{MPh}$ and $\mathrm{MC}$ allow the treated non-wovens to pass in the standard. Finally, considering the results, the following classification for the different formulations can be $\mathrm{mf}_{4}>\mathrm{mf}_{3}>$ $\mathrm{mf}_{5}>\mathrm{mf}_{2}=\mathrm{mf}$. Considering the industrial standards, for a nonwoven of $290 \mathrm{~g} \cdot \mathrm{m}^{-2}$, only the formulations $\mathrm{mf}_{3}$ and $\mathrm{mf}_{4}$ have a commercial potential.

\section{Conclusions}

This work presents the way to develop a new masterbatch from the theoretical concept to the final product. It describes the different steps from the idea to the realization and the evaluation of textile industrial samples. The first study was on the impact of the structure on the final performance. It was shown that for a same formulation, the behavior changes because of the structure and thickness of the 
sample. An increase of the thickness degrades the performance because of the opening of the structure and not because of the efficiency of the FR treatments.

Amongst the different FR tests and standards, it was demonstrated that a mixture of $\mathrm{MPh} / \mathrm{MC}$, added during the spinning into PP, gives flame retardant properties to nonwoven textiles. The ratio of $\mathrm{MPh} / \mathrm{MC}$ was optimized. The ratios of $2 / 1$ and $3 / 1$ give the best performances in term of LOI and cone calorimetry and that with only $6 \mathrm{wt} \%$ of additives, at a ratio $2 / 1$, a nonwoven of PP passes a number of relevant norms with success.

\section{Acknowledgments}

This work was carried out in frame of Intimire program (Intumescent Materials with Improved Fire Retardant and Flame Resistant Properties for Building and Transport Applications) and was supported by European Commission under Seventh Framework Program (Grant agreement No. 243556-2). The authors wish to express their thanks to CREPIM (Centre de Recherche et d'Etudes sur les Procédés d'Ignifugation des Matériaux, Bruay-la-Buissière, France) for cone calorimeter experiments.

\section{Author Contributions}

François Rault and Xavier Almeras designed and performed the research. Francois Rault, Stéphane Giraud, Fabien Salaün and Xavier Almeras analyzed and interpreted data. François Rault, Fabien Salaün and Xavier Almeras wrote the paper.

\section{Conflicts of Interest}

The authors declare no conflict of interest.

\section{References}

1. Aizenshtein, E.M. Polypropylene fibres and yarns in the current state of development. Fibre Chem. 2008, 40, 399-405.

2. Zhang, S.; Horrocks, A.R.; Hull, R.; Kandola, B.K. Flammability, degradation and structural characterization of fibre-forming polypropylene containing nanoclay-flame retardant combinations. Polym. Degrad. Stable 2006, 91, 719-725.

3. Bourbigot, S.; le Bras, M.; Siat, C. Use of polymer blends in flame retardancy of thermoplastic polymers. In Recent Advances in Flame Retardancy of Polymeric Materials; Lewin, M., Ed.; BCC: Norwalk, CA, USA, 1997; Volume 7, pp. 146-160.

4. Bourbigot, S. Flame retardancy of textiles-New approaches. In Advances in Fire Retardant Materials; Horrocks, A.R., Ed.; CRC Press LLC: Cambridge, UK, 2008; pp. 9-40.

5. Pawelec, W.; Aubert, M.; Pfaendner, R.; Hoppe, H.; Wilén, C.-E. Triazene compounds as a novel and effective class of flame retardants for polypropylene. Polym. Degrad. Stable 2012, 97, 948-954.

6. Kaprinidis, N.; King, R.E., III; Shields, P.; Zingg, J.; Leslie, G. Recent advances in flame retardant compositions: UV stable, antimony free flame retardant systems for polypropylene molding. In SPE Polyolefins RETEC; Society of Plastics Engineers: Houston, TX, USA, 2002. 
7. Aubert, M.; Nicolas, R.C.; Pawelec, W.; Wilén, C.-E.; Roth, M.; Pfaendner, R. Azoalkanes-Novel flame retardants and their structure-property relationship. Polym. Adv. Technol. 2011, 22, 1529-1538.

8. Aubert, M.; Roth, M.; Pfaendner, R.; Wilén, C.-E. Azoalkanes: A novel class of additives for cross-linking and controlled degradation of polyolefins. Macromol. Mater. Eng. 2007, 292, 707-714.

9. Nicolas, R.C.; Wilén, C.-E.; Roth, M.; Pfaendner, R.; King, R.E. Azoalkanes: A novel class of flame retardants. Macromol. Rapid Commun. 2006, 27, 976-981.

10. Li, H.; Ning, N.; Zhang, L.; Wang, Y.; Liang, W.; Tian, M. Different flame retardancy effects and mechanisms of aluminium phosphinate in PPO, TPU and PP. Polym. Degrad. Stable 2014, 105, 86-95.

11. Didane, N.; Giraud, S.; Devaux, E.; Lemort, G. Development of fire resistant PET fibrous structures based on phosphinate-poss blends. Polym. Degrad. Stable 2012, 97, 879-885.

12. Naik, A.D.; Fontaine, G.; Samyn, F.; Delva, X.; Bourgeois, Y.; Bourbigot, S. Melamine integrated metal phosphates as non-halogenated flame retardants: Synergism with aluminium phosphinate for flame retardancy in glass fiber reinforced polyamide 66. Polym. Degrad. Stable 2013, 98, 2653-2662.

13. Samyn, F.; Bourbigot, S. Thermal decomposition of flame retarded formulations PA6/aluminum phosphinate/melamine polyphosphate/organomodified clay: Interactions between the constituents? Polym. Degrad. Stable 2012, 97, 2217-2230.

14. Braun, U.; Schartel, B.; Fichera, M.A.; Jäger, C. Flame retardancy mechanisms of aluminium phosphinate in combination with melamine polyphosphate and zinc borate in glass-fibre reinforced polyamide 6,6. Polym. Degrad. Stable 2007, 92, 1528-1545.

15. Fire Behavior of Building Materials and Elements. Part 1: Classification of Building Materials Requirements and Testings; DIN 4102-1; Deutsches Institut für Normung (DIN): Berlin, Germany, 1998.

16. Flammability of Interior Materials-Passengers Cars, Multipurpose Passenger Vehicles, Trucks, and Buses; FMVSS 302; Federal Motor Vehicle Safety Standards (FMVSS): Washington, DC, USA, 1972.

17. Textiles-Determination of Thickness of Textiles and Textile Products; ISO 5084; International Organization for Standardization (ISO): Geneva, Switzerland, 1996.

18. Textiles-Woven Fabrics-Determination of Mass per Unit Length and Mass per Unit Area; ISO 3081; International Organization for Standardization (ISO): Geneva, Switzerland, 1977.

19. Velasco, J.I.; Morhain, C.; Martínez, A.B.; Rodríguez-Pérez, M.A.; de Saja, J.A. The effect of filler type, morphology and coating on the anisotropy and microstructure heterogeneity of injection-moulded discs of polypropylene filled with aluminium and magnesium hydroxides. Part 1. A wide-angle X-ray diffraction study. Polymer 2002, 43, 6805-6811.

20. Reaction to Fire Tests-Heat Release, Smoke Production and Mass Loss Rate-Part 1: Heat Release Rate (Cone Calorimeter Method) and Smoke Production Rate (Dynamic Measurement); ISO 5660-1; International Organization for Standardization (ISO): Geneva, Switzerland, 2013.

21. Railway Applications-Fire Protection on Railway Vehicles-Part 2: Requirements for Fire Behavior of Materials and Components; NF EN 45545-2; Association Francaise de Normalisation: La Plaine Saint-Denis, France, 2013. 
22. Zhang, S.; Horrocks, A.R. A review of flame retardant polypropylene fibres. Prog. Polym. Sci. 2003, 28, 1517-1538.

23. Safety Against Fire: Building Materials-Reaction to Fire Tests-Electrical Burner Test Used for Flexible Materials; NF P92-503; Association Francaise de Normalisation: La Plaine Saint-Denis, France, 1995.

24. Kandola, B.K.; Kandare, E. Composites having improved fire resistance. In Advances in Fire Retardant Materials; Horrocks, A.R., Price, D., Eds.; Woodhead Publishing: Cambridge, UK, 2008; pp. 398-442.

25. Safety Against Fire-Building Materials-Reaction to Fire Tests-Flame Persistence Test and Speed of the Spread of Flame; NF P92-504; Association Francaise de Normalisation: La Plaine Saint-Denis, France, 1995.

26. Salaün, F.; Vroman, I.; Bedek, G.; Lewandowski, M. Effects of microparticles on isotactic polypropylene: Thermomechanical and thermal properties. J. Polym. Sci. Part. B Polym. Phys. 2008, 46, 2566-2576.

27. Salaün, F.; Lewandowski, M.; Vroman, I.; Bedek, G.; Bourbigot, S. Development and characterisation of flame-retardant fibers from isotactic polypropylene melt-compounded with melamine-formaldehyde microcapsules. Polym. Degrad. Stable 2011, 96, 131-143.

28. Dasari, A.; Rohrmann, J.; Misra, R.D.K. On the scratch deformation of micrometric wollastonite reinforced polypropylene composites. Mater. Sci. Eng. 2004, 364, 357-369.

29. Hadal, R.S.; Misra, R.D.K. The influence of loading rate and concurrent microstructural evolution in micrometric talc- and wollastonite-reinforced high isotactic polypropylene composites. Mater. Sci. Eng. 2004, 374, 374-389.

30. Almeras, X.; Dabrowski, F.; le Bras, M.; Poutch, F.; Bourbigot, S.; Marosi, G.; Anna, P. Using polyamide- 6 as charring agent in intumescent polypropylene formulations. I. Effect of the compatibilising agent on the fire retardancy performance. Polym. Degrad. Stable 2002, 77, 305-313.

31. Richard, H.; Lejuste, C. S-Triazine Compounds Possessing Two Substituents Selected from Bulky Para-Aminobenzalmalonate and Para-Aminobenzalmalonamide Groups and One Aminobenzoate Substituent, Compositions and Uses Thereof. Patent EP1642893 A1, 5 April 2006.

32. Li, B.; Xu, M. Effect of novel charring-foaming agent on flame retardancy and thermal degradation of intumescent flame retardant polypropylene. Polym. Degrad. Stable 2006, 91, 1380-1386.

33. Weil, E.D.; Choudhary, V. Flame-retarding plastics and elastomers with melamine. J. Fire Sci. 1995, 13, 104-126.

34. Salaün, F.; Vroman, I. Influence of core materials on thermal properties of melamine-formaldehyde microcapsules. Eur. Polym. J. 2008, 44, 849-860.

35. Braun, U.; Schartel, B. Flame retardancy mechanisms of aluminium phosphinate in combination with melamine cyanurate in glass-fiber-reinforced poly(1,4-butylene terephthalate). Macromol. Mater. Eng. 2008, 293, 206-217.

(C) 2015 by the authors; licensee MDPI, Basel, Switzerland. This article is an open access article distributed under the terms and conditions of the Creative Commons Attribution license (http://creativecommons.org/licenses/by/4.0/). 